\title{
An Enhanced Control Strategy for the Stable Operation of Distributed Generation during Grid-connected and Islanded Mode
}

\author{
Suman Khichar, Yatindra Gopal, Mahendra Lalwani \\ Department of Electrical Engineering, Rajasthan Technical University, Kota, Rajasthan, India
}

\begin{abstract}
Article Info
Article history:

Received Apr 14, 2018

Revised May 20, 2018

Accepted May 29, 2018

\section{Keywords:}

Distributed generation

Islanding detection

Non detection zone

Phase locked loop

Photovoltaic

Point of common coupling

ABSTRACT

The incident of islanding occurs while the distributed generator fed constant power into the grid after power flow on the source of essential utility has been intermittent. If islanding is not rapidly detected, it can reason serious security and harmful condition. This paper presents coordinated manage of solar photovoltaic unit through maximum power point tracking technique to make available voltage and frequency support for an islanding condition. In normal condition, structure works as constant current control mode subsequent to islanding the structure switched to voltage control mode. The projected technique is capable to discriminate involving an islanding and a non-islanding occurrence. In this paper phase locked loop detection technique designed for detecting islanding situation is conceded out. The authentication of proposed system is established efficiently using MATLAB/ Simulink environment. The simulated results exhibit that the islanding detection technique has zero nondetection zone property and be able to detect islanding within few seconds.
\end{abstract}

Copyright () 2018 Institute of Advanced Engineering and Science. All rights reserved.

\footnotetext{
Corresponding Author:

Yatindra Gopal,

Department of Electrical Engineering,

Rajasthan Technical University,

Kota, Rajasthan, India.

Email: helloyatin4u@gmail.com
}

\section{INTRODUCTION}

The inverter-based distributed generation (DG) system incorporated by renewable energy such as photovoltaic, wind power and fuel cell etc. toward supply power intended for the network and local load. Photovoltaic energy have turn out to be more prominent for DG system when compare to other renewable energy resources [1-2]. It is being extensively applied to shelter environment and makes the power industry enlargement sustainable. In regulate to formulate certain the safe operation in cooperation the arrangement and the DG, the DG has to be operational with islanding detection utility [3-4]. Islanding is the condition of creating Power Island like a segment of the utility scheme in case of a widespread interruption in the central power grid. All through islanding conditions constant power provide to load is maintained smooth in a case of main grid stoppage and DG source energizes the load pending the main grid is resynchronized through DG [5]. A maximum disruption of 2 seconds is essential for the islanding detection study wherever scattered network, RLC load and DG system are associated at the point of common coupling (PCC) [3-4]. The study of islanding circumstances can be sub-divided into three sections i.e. the arrangement of islanding, operation during islanding and resynchronization [6-10]. 
The technique of islanding detection classified mainly remote and local. The local methods auxiliary classify in passive or active. Passive method has huge nondetection zone (NDZ) and depending on the situation will not be accomplished to identify islanding. Active methods have smaller NDZ, except it causes extra current harmonics problems [11]. Remote method support detection has a just right concert, although the system and process cost is extremely prominent, required telecommunication strategy and sensors installed on the side of utility. According to the drawbacks of remote and local methods, the hybrid method is a better performance, reduce NDZ, superior power quality and system cost are cheaper [12].

This paper presents islanding detection technique of DG system through phase locked loop (PLL). PLL consists of two loops i.e. an inner loop scheming the DC link voltage and an outer loop scheming the active $\left(I_{d}\right)$ with reactive $\left(I_{q}\right)$ orthogonal current components. The object of the islanding detection technique is to eliminate the NDZ and detection time meets the requirement set out in the standards. The used of the DCDC boost converter to eliminating the additional controller for steadiness the DC link voltage, where a appropriate assortment of inductor and capacitor is important.

The description of this paper classified in following section: section 2 provides problem formulation of islanding detection and overview of the islanding recognition techniques with system study of islanding detection illustrate in section 3. Section 4 describes modeling of PV module, maximum power point tracking (MPPT) technique, a design of the boost converter and inverter control strategy with a discussion of PLL and proportional-integral (PI) regulator. MATLAB based simulation results for predictable technique is presented in section 5 and overall conclusion of this paper is presented in section 6 .

\section{PROBLEM FORMULATION}

The voltage and frequency are coordinated by the electric power system, when a main grid is working in healthy condition. However, when a fault occurs to the utility grid, these values are no longer recognized and they are strongly dependent on the local load associated in the direction of the PCC. The locally distributed generator and its interaction with the local load, on the other hand may cause dangerous situations not only to the equipment but to personnel. The IEEE standard 929-2000 was created to provide strategy, which frequency and voltage restrictions the distribution grid [3-4]. Table 1 show the frequency and voltage limits intended for the utility grid.

Table 1. Islanding Detection Time of Frequency and Voltage Limits for the IEEE STD 929-2000

\begin{tabular}{ccc}
\hline Parameters & Range & Detection time (cycles) \\
\hline \multirow{2}{*}{ Frequency $(\mathrm{Hz})$} & Frequency $<59.3$ & 6 \\
& Frequency $>60.5$ & 6 \\
& Voltage $<50$ & 6 \\
Nominal voltage $(\%)$ & $50 \leq$ Voltage $<88$ & 120 \\
& $88 \leq$ Voltage $<110$ & normal operation \\
& $110 \leq$ Voltage $<137$ & 120 \\
& $137 \leq$ Voltage & 2 \\
\hline
\end{tabular}

The main situation is correlated to the unceasing power insertion by the DG after the main grid is not there. This happens when the voltage and frequency limits correspond with those determined through standard at the instant of islanding. Algorithm presents delineate of the pseudo code intended for islanding detection.

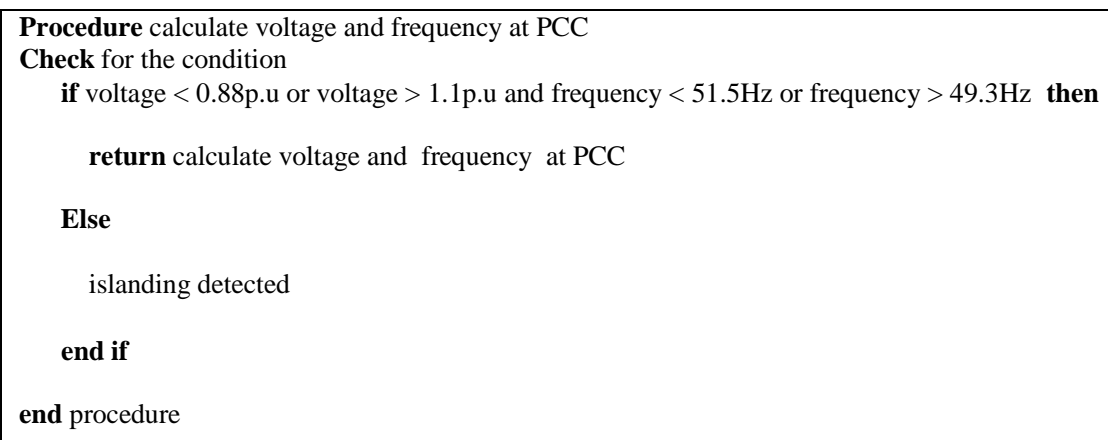

Algorithm: Pseudo code for islanding detection 
The islanding detection techniques have been developed to speed up the islanding detection so as to meet the detection situation in time of the standards.

\section{ISLANDING DETECTION TECHNIQUES}

\subsection{Islanding detection techniques: overview}

Islanding detection methods can be commonly categorized into two types: local and remote method. Local methods be further sub-divided into the passive, active and hybrid method. Remote method is further subdivided into utility and communication-based method [13-16]. Categorization of islanding detection techniques describes in Figure 1.

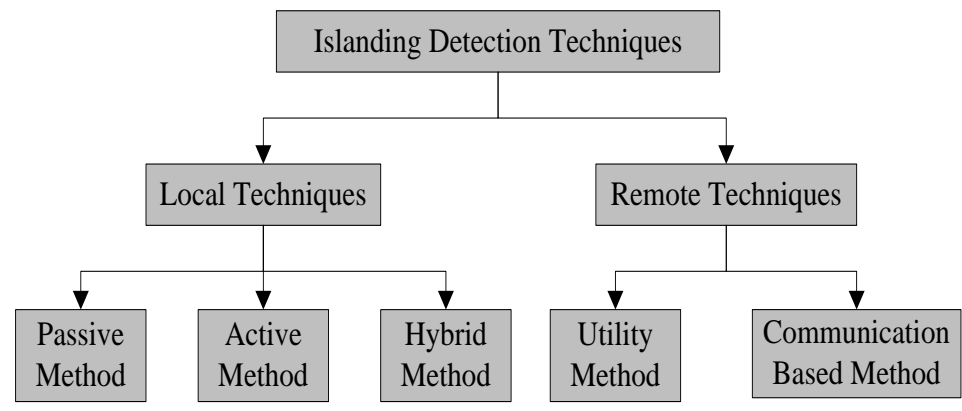

Figure 1. Categorization of islanding detection techniques

Table 2 shows the various islanding detection methods and their performances during operational principle, the size of NDZ, detection time, power quality disturbances, system cost, multiple DGs operation, an effect on the distribution system and influence by the number of connected inverters [17-19].

Table 2. Comparison of islanding detection method based on different parameters

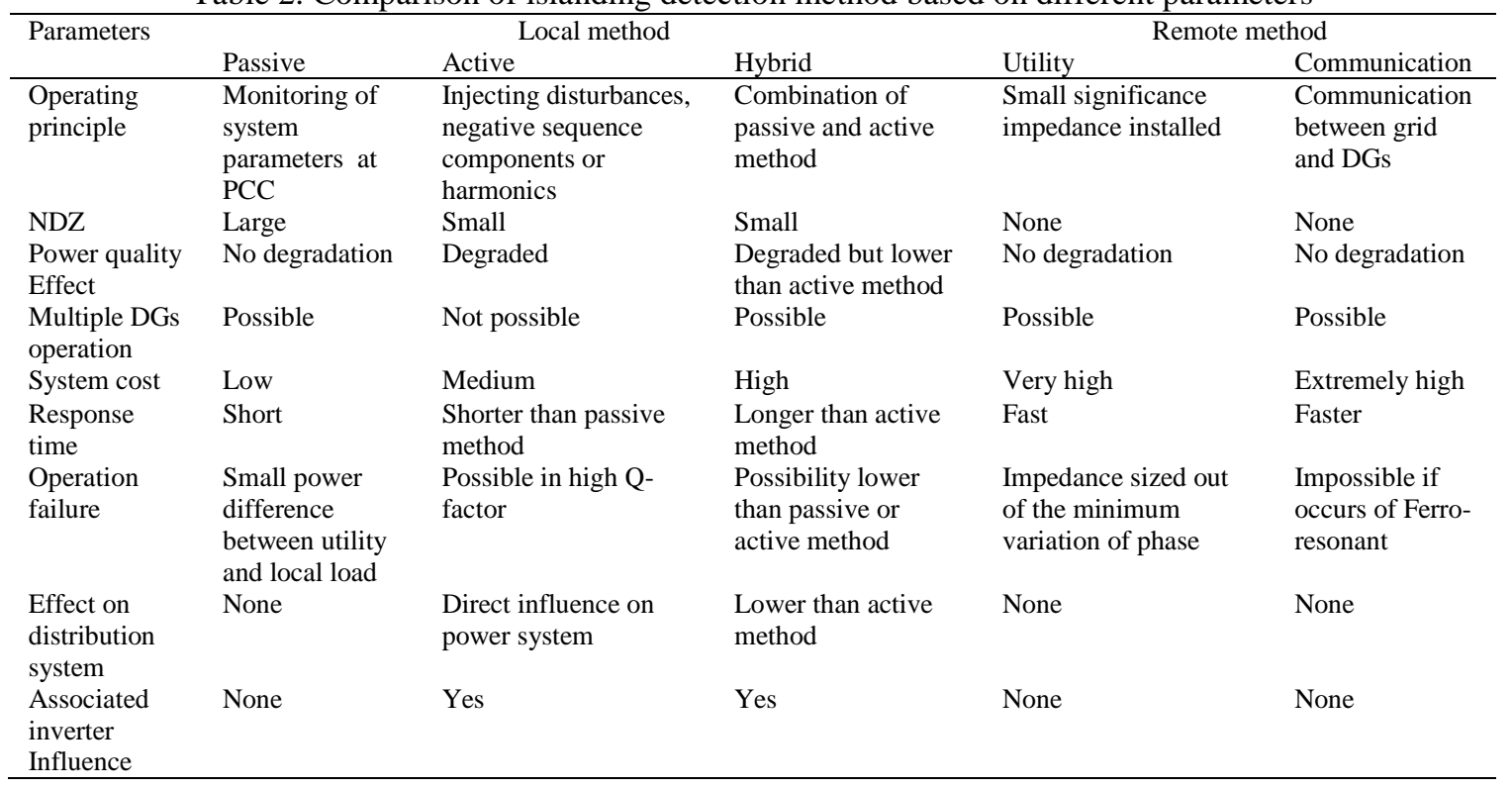

The remote method of islanding detection is better than local islanding detection methods, except at the increased cost and complexity [20-23]. Local methods are more preferable because they are dependent on the measurement of local parameters, free from noise in communication, cheaper etc. 


\subsection{System study for islanding detection}

Recommended test study of islanding detection arrangement consists of an inverter-based DG, parallel RLC load and the grid represented through a source following impedance. The equipped mode of the DG depends on whether the circuit breaker is closed or not [3-4]. The inverter-based DG such as photovoltaic structure is usually configured with the MPPT algorithm. Since islanding detection time is extremely small, the output power is able to measure unvarying through the detection. As a result, by a constant DC source following a three-phase inverter, the DG is considered as a unvarying power source. Figure 2 shows the islanding detection system which consists of two modes of operations i.e., grid-connected mode and islanded mode. During the standard operation or grid-connected mode, the DG within the microgrid will be operational in unvarying current control mode and within islanded mode, the current control approach switched to voltage control approach [24].

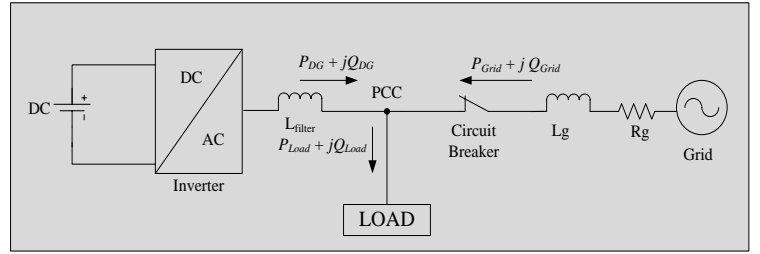

(a) Gridperation-connected o Mode

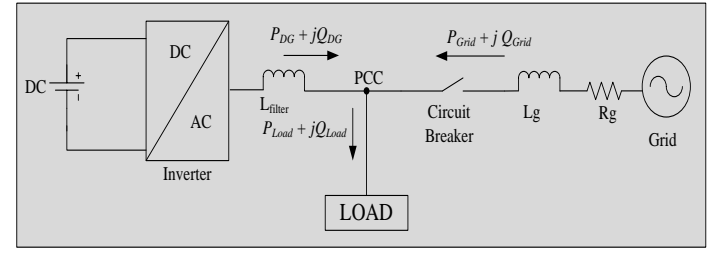

(b) Islanded Operation Mode

Figure 2. Islanding Detection Models

Equation 1 describes the active and reactive power enthusiastic by the load when DG is associated toward the utility grid in grid-connected mode [23-25].

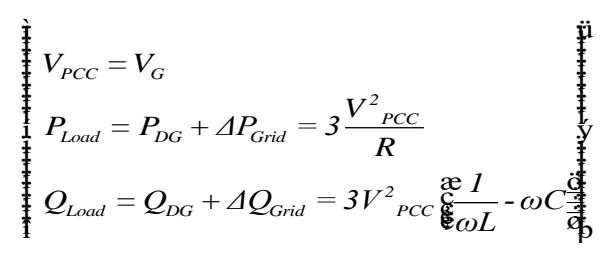

The resonant frequency $\left(f_{L C}\right)$ and quality factor $\left(Q_{f}\right)$ of parallel RLC load are defined like:

$$
\begin{aligned}
& f_{L C}=\frac{1}{2 \pi \sqrt{L C}} \\
& Q_{f}=R \sqrt{\frac{C}{L}}
\end{aligned}
$$

Islanded mode incidental from eq. (1) that if the active power disparity $(\Delta P)=P_{\text {Load }}-P_{D G}=P_{G r i d}$ is not identical to zero. The PCC voltage resolve drop or raise it does not depends on DG operates on unity power factor or not. The quantity of voltage divergence depends upon on the assessment of $\Delta P$. If the active power orientation of the DG is set to be constant, $\Delta P$ can be expressed as follows [24-25]:

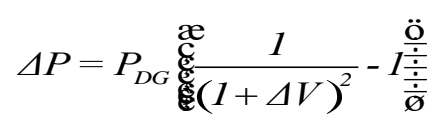

where, $\Delta V$ represents the voltage disparity and it can be expressed as:

$$
\Delta V=\frac{V_{P C C . i}-V_{P C C}}{V_{P C C}}
$$

where $V_{P C C}$ and $V_{P C C . i}$ describes the PCC voltage before and after islanding. 


\section{PROPOSED TECHNIQUE}

Three-phase two-stage grid-connected inverter is collected of two conversion stages, the first-stage is DC-DC boost converter i.e. used to boost the PV section output voltage and organize the PV voltage which regulates the operation of a module at maximum power point (MPP). The regulated voltage of DC-DC boost converter is attended to the DC link, which is an input of the DC-AC inverter. The DC-AC inverter suitable for maintaining the DC link voltage and control the output current. PLL intended for AC power output of the inverter is synchronized with the grid and islanding detection purpose when grid frequency and voltage is below and above IEEE standards limits. The explanation of proposed technique is categorized in following i.e. modeling of $\mathrm{PV}$ module, maximum power point tracking $(\mathrm{P} \& \mathrm{O})$, a design of boost converter and inverter control strategy.

\subsection{Modeling of PV module}

A photovoltaic module is created by concerning many solar cells in series and parallel, it consists of a current source, a diode, and series-parallel arrangement resistors as seen from Figure 3.

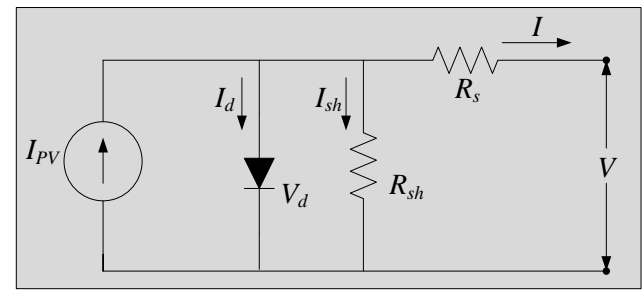

Figure 3. Equivalent circuit of single diode PV module

The characteristic equation for a photovoltaic cell is specified by [26-29]:

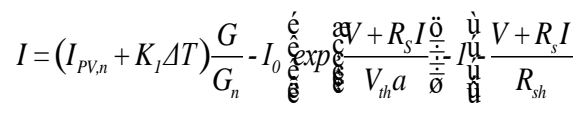

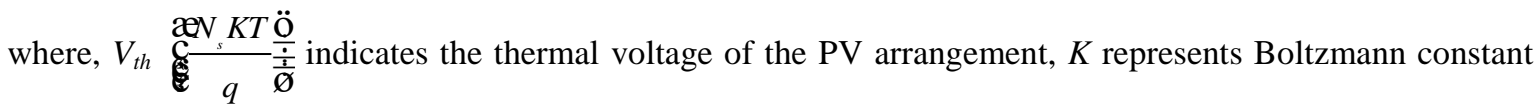
$\left(1.3806503 * 10^{-23} \mathrm{~J} / \mathrm{K}\right), a$ represents ideality factor generally preferred in the range $1 \leq a \leq 1.5, q$ indicates electron charge $\left(1.60217646^{*} 10^{-19} \mathrm{C}\right)$.

\subsection{Maximum power point tracking}

Perturb and observe $(\mathrm{P} \& \mathrm{O})$ algorithm is extensively used in MPPT because of their simple structure and real-time implementation is easy. By the help of MPPT controller, produce duty cycle to trigger the boost converter switch [30-31]. The mathematical illustration of $\mathrm{P} \& \mathrm{O}$ algorithm [32] is given as follows

$$
\frac{d P}{d V_{P V}}(k)=\frac{P(k)-P(k-1)}{V_{P V}(k)-V_{P V}(k-1)}
$$

The operating point is perturbed from time to time by shifting the voltage in PV system. The working voltage of $\mathrm{PV}$ section is disconcerted by a small rise and the consequential change in power $(\Delta \mathrm{P})$. If $\Delta \mathrm{P}$ is positive, the working point reached secure to MPP. If $\Delta \mathrm{P}$ is negative, the operating point has moved distant from the MPP and direction of perturbation encouraged inverted reverse towards MPP [32-33].

\subsection{Design of boost converter}

The boost converter is step up the value of input DC voltage and gives by an output. The main components of a boost converter are an inductor, a diode, a capacitor and high-frequency IGBT switch [34-35]. In this paper, the duty cycle of converter switch is generated from MPPT technique and operating switching frequency at high to generate maximum power. Representation circuit diagram of boost converter as depicted in Figure 4. The equations for an inductor (L), a capacitor (C) and Duty cycle (D) are given by [34]: 


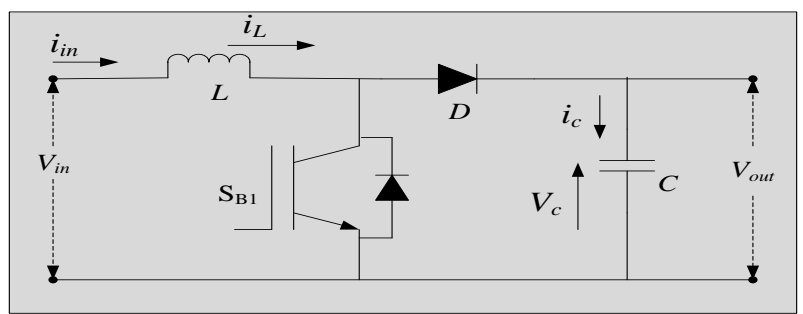

Figure 4. Circuit diagram for boost converter

$$
L=\frac{V_{\text {in }} D T}{\Delta i_{L}} ; C=\frac{V_{0} D}{\Delta V_{0} R f} ; D=\frac{V_{\text {out }}-V_{\text {in }}}{V_{\text {out }}}
$$
period (sec).

here, $\Delta i_{L}$ indicates inductor ripple current and $\Delta V_{0}$ indicates capacitor voltage ripple, $T$ is the time

\subsection{Inverter control strategy}

The control system of an inverter is based on PLL for determination of frequency and voltage to islanding detection. PLL consists of two loops i.e. an outer loop scheming the DC link voltage and an inner loop scheming the active $\left(\mathrm{I}_{\mathrm{d}}\right)$ and reactive $\left(\mathrm{I}_{\mathrm{q}}\right)$ orthogonal current components. The orientation setting for the $I_{d}$ component is determined by an external voltage controller at the same time as the value of the $I_{q}$ component is set to zero to keep up unity power factor. The output power of three-phase inverter is coordinated through grid using a PLL.

PLL is designed for the mainly determination of the frequency and angle orientation at the PCC, it consists of four components i.e. Clark's transformation, Park's transformation, PI regulator and an integrator. dq0 to abc transformation is called Clark's transformation and abc to dq0 transformation is called Park's transformation. These transformations in the PLL method will generate a three-phase balanced waveform through a $120^{\circ}$ phase shift which can be given as input to the inverter. PI regulators are used for scheming the errors in the output of the grid frequency and grid voltage magnitude. Clark's and Park's transformation equation are given below:

Clark's transformation:

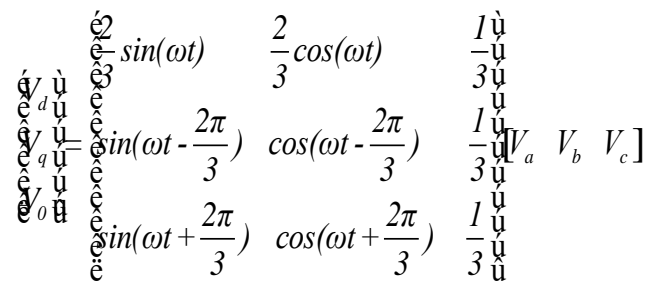

Park's transformation:

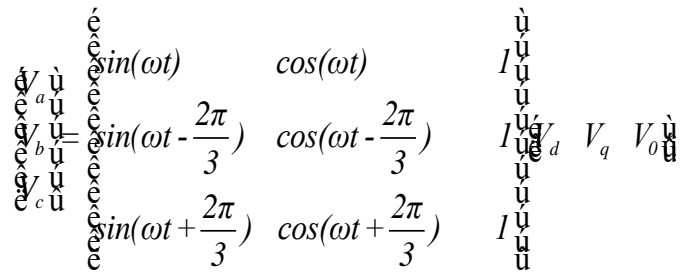

Where, $V_{a}, V_{b}, V_{c}$ are the constant quantity and $V_{d}, V_{q}, V_{0}$ are stipulated quantity of three-phase voltage.

The block diagram of inverter control for projected islanding detection process is specified in Figure 5. It includes three-phase reactive current components, outer voltage loop intended for power control and inner loop intended for grid voltage control. 


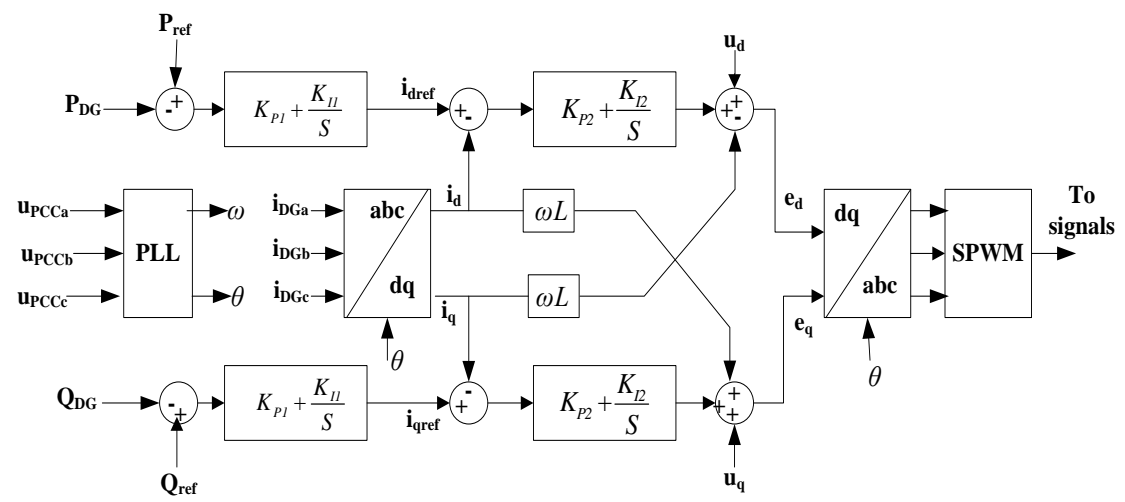

Figure 5. Diagram of inverter control

The projected control system requires two types of measurements i.e. three-phase output currents of the DG $\left(\mathrm{I}_{\mathrm{DG}}\right)$ and a voltage at PCC $\left(\mathrm{V}_{\mathrm{PCC}}\right)$. The $\mathrm{I}_{\mathrm{DG}}$ and $\mathrm{V}_{\mathrm{PCC}}$ are changed into d-q mechanism by the park's transformation. In Figure $6 \mathrm{~d}-\mathrm{q}$ mechanism of currents are denoted by $i_{d}$ and $i_{q}$ and d-q mechanism of voltage are denoted by $u_{d}$ and $u_{q}$. The $i_{d r e f}$ control the active power supplied through the DG while $i_{q r e f}$ controls the reactive power output of the DG, with $i_{\text {qref }}$ set equal to zero rejection reactive power is supplied through the DG and the DG operates at unity power factor. Then by transitory these reference currents during the phase angle transformation $i_{\text {dref }}^{*}$ and $i_{\text {qref }}^{*}$ are obtained by Equation. (10) [34-35].

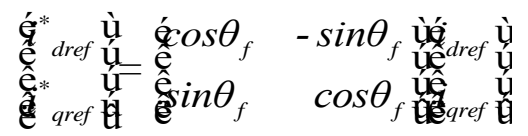

$i_{\text {dref }}^{*}$ and $i_{\text {qref }}^{*}$ are compared with $i_{d}$ and $i_{q}$, which are inverter output currents and pass through a current regulator to the outputs $V_{d r e f}$ and $V_{\text {qref. }} V_{d r e f}$ and $V_{\text {qref }}$ transform to $e_{d}$ and $e_{q}$ given with Equation (11).

$$
\begin{aligned}
& \grave{j} e_{d}=V_{d r e f}+V_{d}-L_{f} \omega i_{q} \ddot{\mathrm{i}} \\
& \stackrel{1}{\mathbf{1}} e_{q}=V_{\text {qref }}+V_{q}+L_{f} \omega i_{d} \ddot{\mathbf{y}}
\end{aligned}
$$

The inverter terminal voltages $e_{d}$ and $e_{q}$ are used to evaluate the modulation index and phase angle which are considered from Equation (12).

$$
m=\sqrt{V_{\text {dref }}^{2}+V_{\text {qref }}^{2}} \quad ; f=\tan ^{-1} \frac{V_{\text {qref }}}{V_{\text {dref }}}
$$

When the DG is associated to the utility grid, Equation (13) and (14) describe the power flows and the active and reactive power consumed by the load.

$$
\begin{aligned}
& P_{\text {Load }}=P_{D G}+P_{\text {Grid }}=3 \frac{V_{P C C}^{2}}{R} \\
& Q_{\text {Load }}=Q_{D G}+Q_{\text {Grid }}=3 V_{P C C}^{2}\left(\frac{1}{2 \mathrm{p} f L}-2 \mathrm{p} f C\right)
\end{aligned}
$$

It can be incidental from Equation (13) that if $P_{\text {Grid }}$ is not zero earlier than the grid detachment, the PCC voltage will collapse or go up during islanding because of the active power disparity $\Delta P\left(\Delta P=P_{\text {Load }}\right.$ $\left.P_{D G}\right)$. Thus, the voltage dissimilarity can be utilized to detect the islanding and the quantity of voltage divergence depends on the value of active power mismatch. If the active power of DG is set constant, the active power disparity can be expressed as follows: 


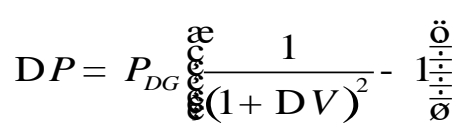

and $\Delta \mathrm{V}$ can be expressed as

$$
\mathrm{D} V=\frac{V_{P C C}^{*}-V_{P C C}}{V_{P C C}}
$$

Similarly, it can be seen from Equation (12) that the amount of disparity in the frequency depends on the significance of both active and reactive power disparity previously islanding occurs. If the DG operates at a unity power factor and there is rejection active power disparity throughout islanding, the reactive power divergence $\Delta \mathrm{Q}\left(\Delta \mathrm{Q}=\mathrm{Q}_{\mathrm{Load}}-\mathrm{Q}_{\mathrm{DG}}\right)$ can be written in expressions of the frequency disparity as follows:

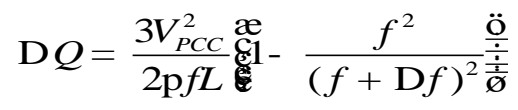

and $\Delta \mathrm{f}$ can be expressed as

$$
\mathrm{D} f=f^{*}-f
$$

SPWM is implemented to establish the on-off signals of inverter switches. This category of interface can organize the DG active and reactive power output.

\section{RESULTS AND DISCUSSIONS}

In this section of the paper, the result of projected method to detection islanding mode is designed for the MATLAB platform. For checking the islanding condition circuit breaker on the utility side is twisted to the open condition. The projected islanding detection technique is implemented with a PV-based inverter and intended to reenergize the system when islanding is detected. The main system parameters are given in Table 3.

Table 3. Parameters of the System Study

\begin{tabular}{cc}
\hline Parameter & Value \\
\hline PV array maximum power output & $100 \mathrm{~kW}$ \\
DC link voltage & $317 \mathrm{~V}$ \\
Inverter switching frequency & $1980 \mathrm{~Hz}$ \\
Filter resistance & $2 \mathrm{~m} \Omega$ \\
Filter inductance & $0.2 \mathrm{mH}$ \\
Load active power & $100 \mathrm{~kW}$ \\
Load quality factor & 1 \\
Grid frequency & $60 \mathrm{~Hz}$ \\
Grid short-circuit power & $2500 \mathrm{MVA}$ \\
Grid X/R ratio & 7 \\
\hline
\end{tabular}

The amount of output power generate by PV module depends on operating voltage of the array. The output voltage and current of the MPPT based PV structure devoid of boost shown in Figure 6 .

The generated duty cycle from the MPPT algorithm width of the pulse is modified according to desired output, generated output duty cycle pulse through MPPT which gives to converter switch is shown in Figure 7.

To an increase the desired level of PV output voltage it interfaces with a DC-DC boost converter. The voltage should be increase from $80 \mathrm{~V}$ to $317 \mathrm{~V}$ approximately. The boosted output voltage from DC-DC converter shown in Figure 8.

Figure 9 shows the voltage and current of the inverter and Figure 10 show the supply voltage of the main grid. Initially the system in grid-connected mode, at 0.1 second there is a disparity in the main grid through changing the voltage. In the same way there is a change in inverter part which is instead of the 
islanding. The voltage change deliberately creating an annoyance in the main grid. This disturbance is detecting by the breaker switch by the help of interval investigation in the inverter elevation which is detecting main grid frequency and voltage. At 0.1 second the limits of voltage are exceeding. So, the breaker switch is shedding the microgrid from the main grid. There will be a disparity occurs in all parameters like voltage, current, and power of the scheme. This disparity in voltage, current, and power is balanced with the help of the DG structure for the duration of the islanding mode of operations.

Harmonic patterns under grid-connected mode i.e. the grid supports local load and exports power toward the grid as shown in Figure 11. From Figure 11 it is observed that the low order harmonics $(\mathrm{THD}=1.04 \%)$ are presented in FFT plot.

Simulation FFT investigation for islanded mode i.e. the inverter supports local load and exports zero power to the grid, are shown in Figure 12.

Figure 13 shows simulation results of inverter voltage at PCC when the islanding detected within 0.002 second. It is established that the islanding can be detected effectively and the detection time is in 2 seconds when the projected technique is applied.
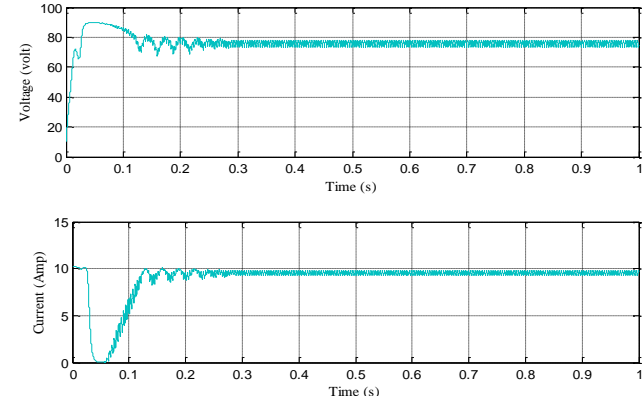

Figure 6. Output voltage and current of MPPT based PV module without boost

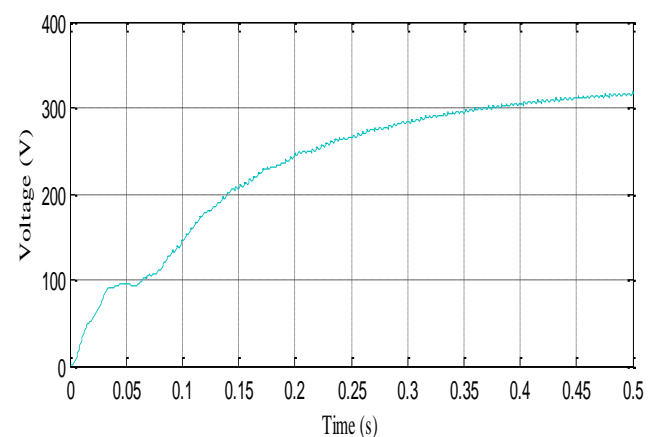

Figure 8. DC-DC converter output between voltage (Volt) and time (s)

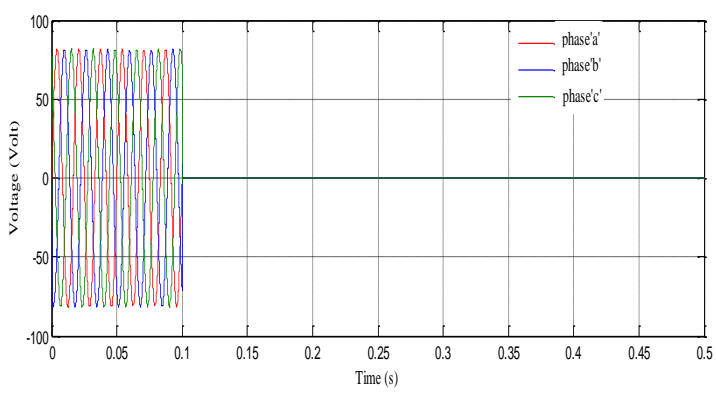

Figure 10. Grid output voltage

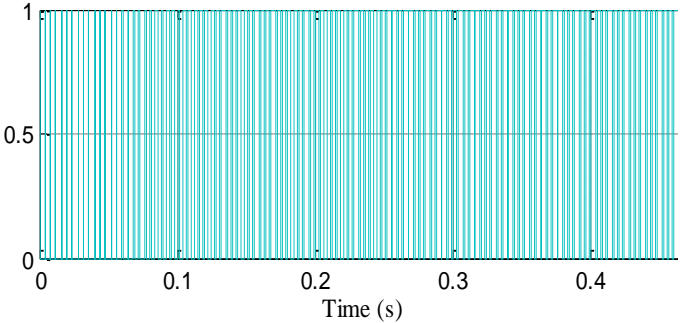

Figure 7. Duty cycle output of MPPT P\&O algorithm
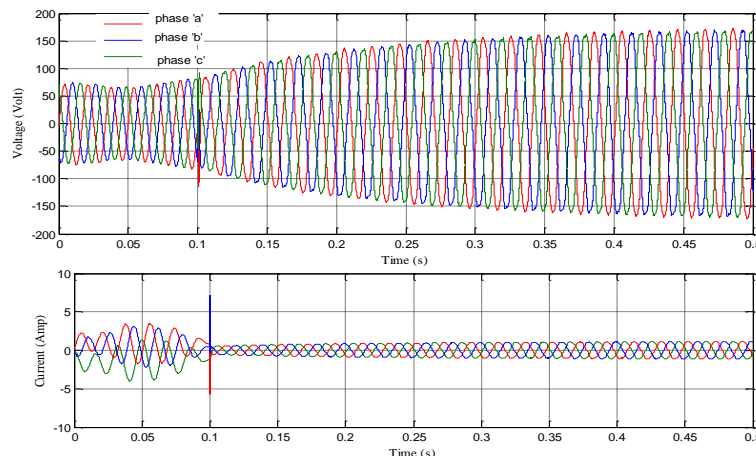

Figure 9. Output of inverter voltage and current

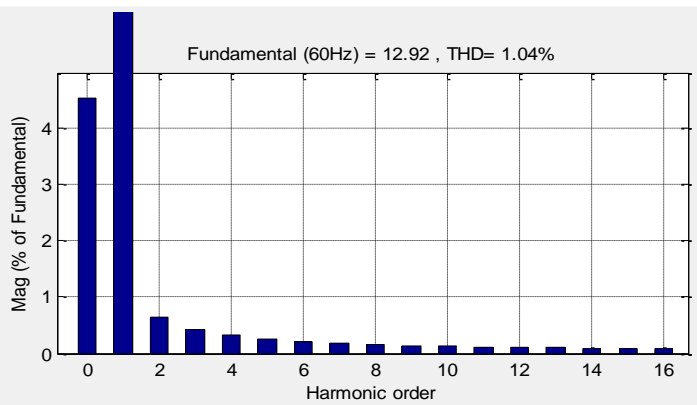

Figure 11. Simulation FFT analysis for grid current in phase ' $a$ ' 


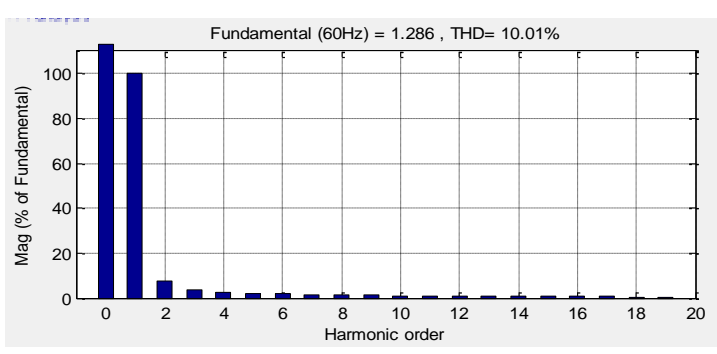

Figure 12. Simulation FFT plot for inverter current in phase ' $\mathrm{a}$ '

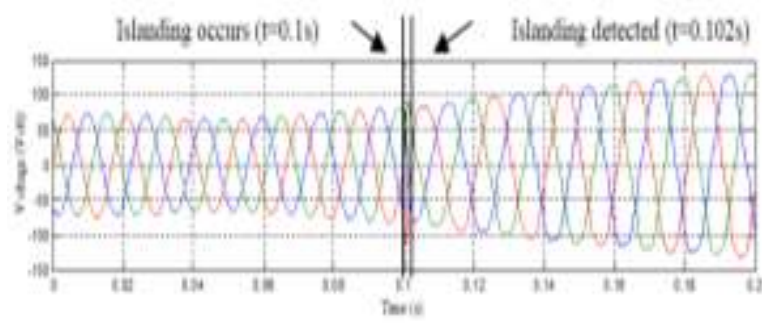

Figure 13. Output inverter voltage when islanding detected

Table 4 shows the comparison of values during grid-connected and islanding mode based on different parameters.

The comparison between passive, active and projected islanding detection procedure, it is observed that the passive technique have short detection time but large NDZ, active technique small NDZ but long detection time. The projected technique has no NDZ and medium detection time. Table 5 shows the comparative investigation of passive, active and proposed technique.

Table 4. Comparison of Different Parameters in Grid-connected and Islanded Mode

\begin{tabular}{ccc}
\hline S. No & Based on & Value \\
\hline 1 & THD (Grid-Connected Mode) & $1.04 \%$ \\
2 & THD (Islanding Connected Mode) & $10.01 \%$ \\
3 & Islanding Occurs Time & $0.1 \mathrm{~s}$ \\
4 & Islanding Detected Time & $0.102 \mathrm{~s}$ \\
5 & Non Detection Zone & 0 \\
6 & Impact on System & Not Significant \\
7 & Ability to Reconnect Grid & Yes \\
8 & Impact on Power Quality & No \\
\hline
\end{tabular}

Table 5. Comparison between the Projected and Classical Islanding Detection Techniques

\begin{tabular}{ccc}
\hline Techniques & Non-detection zone & Detection time \\
\hline Passive & Large NDZ & Short \\
Active & Small NDZ & Long \\
Proposed approach & Zero & 0.002 second \\
\hline
\end{tabular}

The comprehensive investigation of passive, active and projected technique based on NDZ and detection time. The proposed technique is appropriate for islanding detection for the reason that of no NDZ and very short detection time.

\section{CONCLUSION}

In this paper, voltage and frequency control for islanding detection scheme has been projected for the operation of the islanded and grid-connected mode is demonstrated through MATLAB Simulink. In ordinary condition system supports constant control mode of current after islanding, scheme switched to voltage control mode. The PLL is intended for the determination of PCC reference frequency and angle. In a PLL, PI regulator is used for controlling the output inaccuracy of frequency and voltage magnitude of a grid. The comparative analysis based on passive, active and proposed approach, in proposed technique islanding detection time is 0.002 second which is suitable for IEEE standard and NDZ is zero. 


\begin{tabular}{|c|c|c|c|}
\hline \multicolumn{4}{|c|}{ Nomenclature } \\
\hline$V_{P C C}$ & PCC voltage before islanding & $\Delta T$ & $\begin{array}{l}\text { Difference between nominal and } \\
\text { actual temperature }\end{array}$ \\
\hline$V_{G}$ & Grid voltage & $P(k)$ & Present power \\
\hline$P_{D G}$ & Inverter active power & $P(k-1)$ & Previous computed power \\
\hline$Q_{D G}$ & Inverter reactive power & $V_{P V}(k)$ & PV present voltage \\
\hline$P_{\text {Grid }}$ & Grid supply power & $V_{P V}(k-1)$ & PV previous voltage \\
\hline$i_{\text {dref }}$ & DG reference active current & $m$ & Modulation index \\
\hline$i_{\text {qref }}$ & DG reference reactive current & $\phi$ & Phase angle \\
\hline$I_{0}$ & Saturation current of diode & $L_{f}$ & Inductance of filter \\
\hline$N_{s}$ & Series connected cell & $R_{s}$ & Equivalent PV array series resistance \\
\hline$T$ & $\begin{array}{l}\text { Diode } \mathrm{p}-\mathrm{n} \text { junction } \\
\text { temperature }\end{array}$ & $R_{s h}$ & Equivalent PV array shunt resistance \\
\hline$I_{P V, n}$ & $\begin{array}{l}\text { Photocurrent at standard } \\
\text { analysis condition }\end{array}$ & $P_{\text {Load }}$ & Load active power \\
\hline$K_{l}$ & $\begin{array}{l}\text { Short circuit current } \\
\text { /temperature coefficient }\end{array}$ & $Q_{\text {Load }}$ & Load reactive power \\
\hline$G$ & Irradiation on device surface & $f$ & Grid frequency \\
\hline$G_{n}$ & Nominal irradiation & & \\
\hline
\end{tabular}

\section{REFERENCES}

[1] H. B. Puttgen, P. R. MacGregor and F. C. Lambert, "Distributed generation: Semantic hype or the dawn of a new era?," in IEEE Power and Energy Magazine, vol. 99, no. 1, pp. 22-29, Jan.-Feb. 2003.

[2] D.J. Sundar, M.S. Kumaran, "A comparative review of islanding detection schemes in distributed generation systems," International Journal of Renewable Energy Research, vol. 5, pp. 1016-1023. 2015.

[3] IEEE Recommended Practice for Utility Interface of Photovoltaic (PV) Systems, IEEE Standard 929-2000, April 2000.

[4] IEEE Standard for Interconnecting Distributed Resources with Electric Power Systems, IEEE Standard 1547- 2003, July 2003

[5] X. Renzhong, X. Lie, Z. Junjun, D. Jie, "Design and research on the LCL filter in three-phase PV grid-connected inverters," International Journal of Computer and Electrical Engineering, vol. 5, pp. 322-325, 2013

[6] J.W. Simpson-Porco, F. Dorfler, F. Bullo, "Synchronization and power sharing for droop-controlled inverters in islanded microgrids," Automatica, vol. 49, pp. 2603-2611, 2013.

[7] G. Hernandez-Gonzalez and R. Iravani, "Current injection for active islanding detection of electronically-interfaced distributed resources," in IEEE Transactions on Power Delivery, vol. 21, no. 3, pp. 1698-1705, July 2006.

[8] F. Pilo, G. Celli and S. Mocci, "Improvement of reliability in active networks with intentional islanding," 2004 IEEE International Conference on Electric Utility Deregulation, Restructuring and Power Technologies. Proceedings, Hong Kong, China, 2004, pp. 474-479 Vol.2.

[9] H. Pourbabak, A. Akhlaghi, "A new technique for islanding detection using voltage phase angle of inverter-based DGs," International Journal of Electrical Power and Energy System, vol. 57, pp. 198-205, 2014.

[10] Qin Lei, F. Z. Peng and I. J. Balaguer, "Islanding control of DG in microgrids," 2009 IEEE 6th International Power Electronics and Motion Control Conference, Wuhan, 2009, pp. 450-455.

[11] B. Yu, M. Matsui and G. Yu, "A Correlation-Based Islanding-Detection Method Using Current-Magnitude Disturbance for PV System," in IEEE Transactions on Industrial Electronics, vol. 58, no. 7, pp. 2935-2943, July 2011.

[12] S.P. Chowdhury, S. Chowdhury, P.A. Crossley, "Islanding protection of active distribution networks with renewable distributed generators: a comprehensive survey," Electric Power Systems Research, vol. 79, pp. 984-992, 2009.

[13] H. Pourbabak, A. Kazemi, "Islanding detection method based on a new approach to voltage phase angle of constant power inverters," IET Generation, Transmission and Distribution, vol. 10, pp. 1190-1198, 2016.

[13] H. Pourbabak and A. Kazemi, "Islanding detection method based on a new approach to voltage phase angle of constant power inverters," in IET Generation, Transmission \& Distribution, vol. 10, no. 5, pp. 1190-1198, 74 2016.

[14] Zhihong Ye, A. Kolwalkar, Yu Zhang, Pengwei Du and Reigh Walling, "Evaluation of anti-islanding schemes based on nondetection zone concept," in IEEE Transactions on Power Electronics, vol. 19, no. 5, pp. 1171-1176, Sept. 2004.

[15] H. H. Zeineldin, E. F. El-Saadany and M. M. A. Salama, "Impact of DG interface control on islanding detection and nondetection zones," in IEEE Transactions on Power Delivery, vol. 21, no. 3, pp. 1515-1523, July 2006.

[16] F. De Mango, M. Liserre and A. Dell'Aquila, "Overview of Anti-Islanding Algorithms for PV Systems. Part II: ActiveMethods," 2006 12th International Power Electronics and Motion Control Conference, Portoroz, 2006, pp. 1884-1889. 
[17] A. Yafaoui, B. Wu and S. Kouro, "Improved Active Frequency Drift Anti-islanding Detection Method for Grid Connected Photovoltaic Systems," in IEEE Transactions on Power Electronics, vol. 27, no. 5, pp. 2367-2375, May 2012.

[18] H. Vahedi and M. Karrari, "Adaptive Fuzzy Sandia Frequency-Shift Method for Islanding Protection of InverterBased Distributed Generation," in IEEE Transactions on Power Delivery, vol. 28, no. 1, pp. 84-92, Jan. 2013.

[19] H. Karimi, A. Yazdani and R. Iravani, "Negative-Sequence Current Injection for Fast Islanding Detection of a Distributed Resource Unit," in IEEE Transactions on Power Electronics, vol. 23, no. 1, pp. 298-307, Jan. 2008.

[20] O. Raipala, A. Mäkinen, S. Repo and P. Järventausta, "An Anti-Islanding Protection Method Based on Reactive Power Injection and ROCOF," in IEEE Transactions on Power Delivery, vol. 32, no. 1, pp. 401-410, Feb. 2017.

[21] E. J. Estebanez, V. M. Moreno, A. Pigazo, M. Liserre and A. Dell'Aquila, "Performance Evaluation of Active Islanding-Detection Algorithms in Distributed-Generation Photovoltaic Systems: Two Inverters Case," in IEEE Transactions on Industrial Electronics, vol. 58, no. 4, pp. 1185-1193, April 2011.

[22] M. Mehrasa, E. Pouresmaeil, B.N. Jorgensen, P.S. Catalao, "A control plan for the stable operation of microgrids during grid-connected and islanded modes," Electrical Power Systems Research, vol. 129, pp. 10-22, 2015.

[23] D. Reigosa, F. Briz, C. Blanco, P. García and J. Manuel Guerrero, "Active Islanding Detection for Multiple Parallel-Connected Inverter-Based Distributed Generators Using High-Frequency Signal Injection," in IEEE Transactions on Power Electronics, vol. 29, no. 3, pp. 1192-1199, March 2014.

[24] J. Merino, P. Mendoza-Araya, G. Venkataramanan and M. Baysal, "Islanding Detection in Microgrids Using Harmonic Signatures," in IEEE Transactions on Power Delivery, vol. 30, no. 5, pp. 2102-2109, Oct. 2015.

[25] X. Chen and Y. Li, "An Islanding Detection Algorithm for Inverter-Based Distributed Generation Based on Reactive Power Control," in IEEE Transactions on Power Electronics, vol. 29, no. 9, pp. 4672-4683, Sept. 2014.

[26] M. G. Villalva, J. R. Gazoli and E. R. Filho, "Comprehensive Approach to Modeling and Simulation of Photovoltaic Arrays," in IEEE Transactions on Power Electronics, vol. 24, no. 5, pp. 1198-1208, May 2009.

[27] M. G. Villalva, J. R. Gazoli and E. R. Filho, "Modeling and circuit-based simulation of photovoltaic arrays," 2009 Brazilian Power Electronics Conference, Bonito-Mato Grosso do Sul, 2009, pp. 1244-1254.

[28] R. Sridhar, D. Jeevananathan, N.T. Selvan, S. Banerjee, "Modeling of PV array and performance enhancement by MPPT algorithm," International Journal of Computer Applications, vol. 7, pp. 35-39, 2010.

[29] S. Adhikari and F. Li, "Coordinated V-f and P-Q Control of Solar Photovoltaic Generators With MPPT and Battery Storage in Microgrids," in IEEE Transactions on Smart Grid, vol. 5, no. 3, pp. 1270-1281, May 2014.

[30] K. Ishaque, Z. Salam, G. Lauss, "The performance of perturb and observe and incremental conductance maximum power point tracking method under dynamic weather conditions," Applied energy, vol. 119, pp. 228-236, 2014.

[31] M. A. Elgendy, B. Zahawi and D. J. Atkinson, "Assessment of Perturb and Observe MPPT Algorithm Implementation Techniques for PV Pumping Applications," in IEEE Transactions on Sustainable Energy, vol. 3, no. 1, pp. 21-33, Jan. 2012.

[32] Y. Gopal, K. Kumar, D. Birla, M. Lalwani, "Banes and boons of perturb \& observe, incremental conductance and modified regula falsi method for sustainable PV energy generation," Journal of Power Technologies, vol. 97, pp. 1-9, 2017.

[33] G. Buticchi, D. Barater, E. Lorenzani, C. Concari and G. Franceschini, "A Nine-Level Grid-Connected Converter Topology for Single-Phase Transformerless PV Systems," in IEEE Transactions on Industrial Electronics, vol. 61, no. 8, pp. 3951-3960, Aug. 2014

[34] N. Prabaharn, K. Palanisamy, "Analysis and integration of multilevel inverter configuration with boost converters in a photovoltaic system," Energy Conversion and Management, vol. 128, pp. 327-342, 2016.

[35] A. Kalirasu, S.S. Dash, "Simulation of closed loop controlled boost converter for solar installation," Serbian Journal of Electrical Engineering, vol. 7, pp. 121-130, 2010. 